\title{
VIII. On certain criteria of imaginary roots of equations
}

\section{J.R. Young}

To cite this article: J.R. Young (1846) VIII. On certain criteria of imaginary roots of equations, Philosophical Magazine Series 3, 29:191, 32-34, DOI: 10.1080/14786444608562595

To link to this article: http://dx.doi.org/10.1080/14786444608562595

曲 Published online: 30 Apr 2009.

Submit your article to this journal $\pi$

Џll Article views: 2

Q View related articles $\longleftarrow$ 
100 parts of cryptolite gave,-

$$
\begin{aligned}
& \text { Peroxide of cerium . } \quad \begin{array}{r}
73 \cdot 70 \\
\text { Protoxide of iron. : } \\
\text { Phosphoric acid . } \\
\hline
\end{array} \frac{27 \cdot 37}{102 \cdot 58}
\end{aligned}
$$

The excess arises from the cerium having been determined as peroxide instead of protoxide, in which latter form it evidently exists in the mineral. Whether the oxide of cerium is mixed with the oxides of didymium and lanthanium must at present remain undetermined, no sure method of separating these oxides from each other being known. The colour of the oxide obtained was dark cinnamon-brown, and evidently contained no zirconia or thorina. The absence of this latter distinguishes the mineral from monazite and edwardsite. Comparative experiments made with monazite and cryptolite left no doubt that they were perfectly distinct.

In conclusion, I may mention that cryptolite is either not quite insoluble in nitric acid, or the apatite of Arendal contains another cerium mineral which is soluble; it may possibly be monazite. On separating cryptolite and precipitating the saturated solution of apatite in nitric acid by an excess of oxalate of potash, washing and heating the precipitate to redness, and dissolving the carbonate of lime thus obtained in nitric acid, there remained a grayish earthy powder undissolved. Muriatic acid dissolved this powder, leaving a quantity of fluoride of calcium. The solution, evaporated down and mixed with a boiling-hot saturated solution of sulphate of potash, deposited in considerable quantity a powdery, pale, amethyst-coloured precipitate of the double salt of potash and cerium-oxide, which, decomposed by potash, gave a cinnamonbrown coloured oxide of cerium.

VIII. On certain Criteria of Imaginary Roots of Equations. By J. R. Young, Professor of Mathematics Belfast College*.

A T page 450 of vol. xxiii. of this Magazine, I gave certain $A$ new criteria for the imaginary roots of numerical equations. These, in conjunction with the long-neglected criteria of Newton, were shown to be of some value in facilitating inquiries into the character of the roots of an equation, as by their aid the mere inspection of the coefficients would often supply the information not otherwise to be obtained without a lengthy and laborious analysis. The formulas referred to

* Communicated by the Author. 
admit of extension: giving rise to other criteria that may sometimes apply where known tests fail, and which, as well on this account as for the purpose of giving completeness to the former set, it may be worth while to record.

The general numerical equation being

$\mathbf{A}_{n} x^{n}+\mathbf{A}_{n-1} x^{n-1}+\mathbf{A}_{n-2} x^{n-2}+A_{n-3} x^{n-3}+\ldots A_{1} x+A_{0}=0$,

the criteria already investigated are

$$
\begin{aligned}
\mathbf{A}_{n} \mathbf{A}_{n-2} & >\mathbf{A}_{n-1}^{2}, \\
\mathbf{A}_{n-1} \mathbf{A}_{n-3} & >\mathbf{A}_{n-2}^{2}, \\
\mathbf{A}_{n-2} \mathbf{A}_{n-4} & >\mathbf{A}_{n-3}^{2}, \\
\vdots & \vdots \\
\mathbf{A}_{2} \mathbf{A}_{0} & >\mathbf{A}_{1}^{2},
\end{aligned}
$$

which are to be applied for the detection of imaginary roots exactly as the criteria of Newton are applied, and as explained in the volume above referred to. To give the proposed extension to these forms, we have only to multiply the several coefficients of the equation-in the manner so often employed by Newton and Maclaurin-by the terms of an arithmetical progression, as $1,2,3,8 \mathrm{c}$., and to replace the original coefficients by the results: we shall thus have the following set of criteria to be applied in the same way as those above:-

$$
\begin{aligned}
3 \mathrm{~A}_{n} \mathrm{~A}_{n-2} & >4 \mathrm{~A}_{n-1}^{2}, \\
8 \mathrm{~A}_{n-1} & \mathrm{~A}_{n-3}>9 \mathrm{~A}_{n-2}^{2}, \\
15 \mathrm{~A}_{n-2} \mathrm{~A}_{n-4} & >16 \mathrm{~A}_{n-3}^{2}, \\
\vdots & \vdots \\
\left(n^{2}-\text { i) } \mathrm{A}_{2} \mathrm{~A}_{0}\right. & >n^{2} \mathrm{~A}_{1}^{2} .
\end{aligned}
$$

But these are only particular cases of the following more comprehensive forms, obtained by means of the general arithmetical progression $k, k+1, k+2, \& \mathrm{c} .:-$

$$
\begin{gathered}
k(k+2) \mathbf{A}_{n} \mathbf{A}_{n-2}>(k+1)^{2} \mathbf{A}_{n-1}^{2}, \\
(k+1)(k+3) \mathbf{A}_{n-1} \mathbf{A}_{n-3}>(k+2)^{2} \mathbf{A}_{n-2}^{2}, \\
(k+2)(k+4) \mathbf{A}_{n-2} \mathbf{A}_{n-4}>(k+3)^{2} \mathbf{A}_{n-3}^{2}, \\
\vdots \\
\vdots \\
(k+n-2)(k+n) \mathbf{A}_{2} \mathbf{A}_{0}>(k+n-1)^{2} \mathbf{A}_{1}{ }^{2} .
\end{gathered}
$$

and in which we may, if we please, write $A_{0}, A_{1}, A_{2}$, \&c. in the place of $\mathbf{A}_{n}, \mathbf{A}_{n-1}, \mathbf{A}_{n-2}$, \&c., and vice versâ.

It will be observed that these criteria are really distinct from the former set, and are not comprehended in that set; for although whenever any one of these holds the correspond-

Phil. Mag. S. 3. Vol. 29. No. 191. July 1846. 


\section{On certain Criteria of Imaginary Roots of Equations.}

ing one in the former set must hold also, yet one of these may fail without any failure in the corresponding form of the preceding set.

The latter forms, when expressed in words, furnish the following rule, which it will be ensy to remember :-

Commencing with the second coefficient and proceeding towards the right, or with the last but one and proceeding towards the left, multiply the successive coefficients by any series of consecutive whole numbers, and square the results: the square of each coefficient will thus be multiplied by an integral square. Let the product of the adjacent coefficients, on each side, be now multiplied by the same square minus 1 ; and compare these results with the former, as in Newton's rule.

Of course criteria of this kind, which are to be applied immediately to the coefficients of the given equation, cannot always be expected to make known the exact number of imaginary roots entering that equation; yet our chances of obtaining this knowledge become multiplied with the number of our distinct and independent tests for the detection of such roots. At present we have no easily applied, and at the same time completely decisive tests of this kind which extend beyond an equation of the third degree; yet, as respects equations of the fourth degree, I think a little may be added in this way, as inferences from the following general expression for two roots of the biquadratic equation-

$$
x^{4}+p x^{2}+q x+r=0
$$

when the other two $x_{1}, \hat{x}_{2}$ are given :-

$$
-\frac{x_{1}+x_{2}}{2} \pm \sqrt{ }\left\{\left(\frac{x_{1}-x_{2}}{2}\right)^{2}+\frac{q}{x_{1}+x_{2}}\right\} * \text {. }
$$

The inferences adverted to are these, viz-c-

Supposing $q$ positive, which is always allowable, we see from this expression that, -

1. If two real roots occur in the positive region, the other two roots must be real also.

2. If two imaginary roots are indicated in the negative region, the others must be imaginary. Therefore,

3. If two real roots are detected, without regard to their situation, and the remaining two are indicated in the negative region, these must be real also; and if two imaginary roots are indicated in either region, and the remaining two are indicated in the positive region, these must be imnginary also.

Belfast, June 11, 1846.

* Analysis, \&c. of Cubic and Biquadratic Equations, p. 235 . 